\title{
TELEMACHUS E A LÍNGUA EMBRIONÁRIA DE JOYCE
}

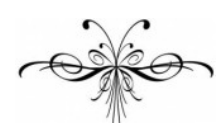

Dirce Waltrick do Amarante \& SÉrgio Medeiros

Resumo: Neste artigo, escrito a quatro mãos, os autores discutem dois "começos". Na primeira parte, eles falam da abertura do romance Ulysses, destacando aspectos de sua tradução ao português; na segunda parte, falam da evolução das línguas, tal como Joyce a representou no mesmo romance, ao propor, em suas páginas, uma língua selvagem, ou vegetal, e uma lingual primordial, composta de formas verbais embrionárias: o começo dos começos

Palavras-chave: Estudos da Tradução; Literatura Irlandesa; Telêmaco; Ulysses; James Joyce.

\begin{abstract}
In this article, written by four hands, the authors discuss two "begginings". First, they examine the opening of Ulysses, highlighting aspects of its translation into Portuguese; later, they deal with the evolution of languages, following Joyce's representation of it in his novel, as he proposed in its pages a wild, or vegetal, language and a primordial language made of embryonic verbal forms: the beginning of various beginnings...
\end{abstract}

Keywords: Translation Studies; Irish Literature; Telemachus; Ulysses; James Joyce.

\section{As primeiras linhas de Ulysses}

um abril de 1922, o escritor irlandês George Moore, numa espécie de repulsa à obra de seu conterrâneo, teria comentado com um amigo: "Alguém recentemente me mandou um exemplar de Ulis- 


\section{Dirce Waltrick do Amarante \& SÉRgio MedeIros}

ses. Disseram-me que o tenho que ler, mas como se pode ler um troço desses?" Prosseguiu: "Ulisses não tem jeito, é absurdo imaginar que se possa atingir qualquer fim bom tentando registrar cada pensamento e sensação de um ser humano."

Ulisses é, ainda hoje, exatamente o que o poeta irlandês William Butler Yeats afirmou no século passado: "uma coisa inteiramente nova - nem o que o olho vê nem o que o ouvido ouve, mas o que a mente errante pensa e imagina, de momento em momento". 2

Se ler Ulisses é uma tarefa "árdua", traduzi-lo é uma possibilidade para bem poucos. No Brasil, contamos agora com três traduções do romance. A tradução pioneira de Ulisses, publicada em 1966, pela editora Editora Civilização Brasileira, foi assinada por Antônio Houaiss; ${ }^{3}$ em 2005, a editora Objetiva publicou uma nova versão da epopeia joyceana, de autoria de Bernardina da Silveira Pinheiro. ${ }^{4}$ Em 2012, ano em que a obra de Joyce caiu em domínio público, a Companhia das Letras lançou uma terceira tradução de Ulysses (com y, como no texto original), assinada pelo paranaense Caetano Waldrigues Galindo, ${ }^{5}$ fruto de dez anos de dedicação e de uma tese de doutorado defendida, em 2006, na Universidade de São Paulo.

Comecemos nos familiarizando com o primeiro capítulo do romance, a partir de sua frase inicial.

Quando "Solene, o roliço Buck Mulligan surgiu no alto da escada" (tradução de Caetano Galindo), eram aproximadamente oito horas da manhã de uma quinta-feira, dia 16 de junho de 1904. Esse capítulo se desenvolve em torno de três personagens os quais se encontram na Martello Tower, em Sandycove, na baía de Dublin: o jovem Stephen Dedalus, de vinte e dois anos, filósofo e poeta; Buck Mulligan, um "alegre parasita", como afirma Vladimir Nabokov, o qual seria "a paródia e a sombra grotesca de Stephen"6 (se Stephen é um jovem sério, torturado pela idéia da morte e da mudança de credo - ele repudia a igreja católica, na qual foi educado -, Mulligan é um falso pagão, feliz e blasfemo). O outro personagem que compõe essa tríade é o inglês Haines, estudante de Oxford, que está em Dublin para recolher o folclore irlandês. Em princípio, Haines não é uma "pessoa má", mas, para Stephen, ele representa a usurpadora Inglaterra:

\section{"Haines desprendeu do lábio inferior algumas fibras de tabaco antes de falar: - Eu bem posso entender isso, disse calmamente. Eu diria que um irlandês tem que pensar assim. Nós sentimos na Inglaterra que fomos bem injustos com vocês. Pa- rece que a história vai levar a culpa." (tradução de Caetano Galindo)}

Diria que a frase inicial de Ulysses - Stately, plump Buck Mulligan came from the stairhead, bearing a bowl of lather on which a mirror and a razor lay crossed. -, a princípio bastante clara, dá o tom das traduções de Houaiss, Pi-

\footnotetext{
${ }^{1}$ ELLMANN, Richard. James Joyce. São Paulo: Globo, 1989, 652 p.

${ }^{2}$ Idem, p. 653.

${ }^{3}$ JOYCE, James. Ulisses. Trad. de Antonio Houaiss. Rio de Janeiro: Civilização Brasileira, 1982.

${ }^{4}$ JOYCE, James. Ulisses. Trad. de Bernardina da Silveira Pinheiro. Rio de Janeiro: Objetiva, 2005.

5 JOYCE, James. Ulysses. Trad. de Caetano Waldrigues Galindo. São Paulo: Penguin / Companhia das Letras, 2012.

${ }^{6}$ NABOKOV, Vladimir. Aulas de literature. Lisboa: Relógio d’água, 2004, p. 334.
} 


\section{TELEMACHUS E A LÍNGUA EMBRIONÁRIA DE JOYCE}

nheiro e Galindo. ${ }^{7}$ A tradução de Houaiss tem um tom austero e imponente: "Sobranceiro, fornido, Buck Mulligan vinha do alto da escada, com um vaso de barbear, sobre o qual se cruzavam um espelho e uma navalha. Seu roupão amarelo, desatado, se enfunava por trás à doce brisa da manhã."

Já Pinheiro, numa tradução mais literal, mantém o coloquialismo da frase joyceana: "Majestoso, o gorducho Buck Mulligan apareceu no topo da escada, trazendo na mão uma tigela com espuma sobre a qual repousavam, cruzados, um espelho e uma navalha de barba. Um penhoar amarelo, desamarrado, flutuando suavemente atrás dele no ar fresco da manhã." Embora Pinheiro se aproxime mais de Joyce do que de Houaiss no que diz respeito ao coloquialismo, não deixa de causar um certo estranhamento ver o imponente Buck Mulligan usando um "penhoar" em vez de um roupão, empregado por Joyce.

Galindo mantém o coloquialismo de Joyce, porém, enfatiza o aspecto sagrado do trecho ao empregar a palavra "cíngulo", cordão que integra a vestimenta dos sacerdotes - esse termo "técnico" não foi usado pelos tradutores anteriores: "Solene, o roliço Buck Mulligan surgiu no alto da escada, portando uma vasilha de espuma em que cruzados repousavam espelho e navalha. Um roupão amarelo, com cíngulo solto, era delicadamente sustentado atrás dele pelo doce ar da manhã."

Como afirma Vladimir Nabokov, Buck Mulligan "vem do cimo das escadas e a navalha da barba cruzados em cima, a salmodiar, como se estivesse a celebrar a missa, as palavras que comemoram na Igreja Católica o sacrifício do corpo e do sangue de Cristo sob a forma de pão e vinho". ${ }^{8}$ Assim se lê no romance:

He held the bowl aloft and intoned:
- Introibo ad altare Dei."
"Elevou a vasilha e entoou:

- Introibo ad altare Dei."

(tradução de Caetano Galindo)

De fato, a vasilha de Buck Mulligan representaria o cálice sagrado, e o alto da escada, os degraus do altar. A navalha indicaria a matança, associando o "padre" ao açougueiro. Joyce usa ainda a palavra ungirdled, que não é apenas "desamarrado", mas refere-se a girdle, uma cinta sacerdotal, o "cíngulo". Segundo Don Gifford, em Ulysses Annotated, ungirdled sugere a violação do voto de castidade por parte do sacerdote. ${ }^{9}$

Um detalhe importante, ainda na primeira página do romance, é a letra "S", que abre o capítulo. Gifford lembra que a primeira parte de Ulysses começa com a letra "S", que representaria o personagem Stephen Dedalus; a segunda parte do romance começa com a letra "M", de Molly Bloom; por fim, a primeira letra da terceira parte do livro é a letra "P", numa alusão a Poldy, abreviatura do nome Leopold (Bloom). Galindo mantém esse "S" inicial (e as demais iniciais do original, em todas as partes de sua tradução), ao traduzir Stately por "Solene". Hoauiss mantém

\footnotetext{
${ }^{7}$ Não tratamos aqui da tradução portuguesa do Ulysses, de João Palma-Ferreira, por entendermos que a ideia de língua portuguesa que se tem em Portugal não é a mesma que se tem no Brasil, testemunho da diferença entre as duas culturas; por esse motivo, empreendemos nossa análise das traduces brasileiras somente.

${ }^{8}$ NABOKOV, Vladimir. Op. Cit., p. 335.

${ }^{9}$ GIFFORD, Don. Ulysses Annotated. Berkeley: University of California Press, 1988, p. 13.
} 


\section{Dirce Waltrick do Amarante \& SÉRgio MedeIros}

o "S", na primeira parte de Ulysses, traduzindo Stately por "Sobranceiro", e mantém a letra "P" na terceira parte, mas, na segunda parte do livro, substitui o "M" pela letra "L". Já Pinheiro parece não ter levado em conta, na sua tradução, essas iniciais em nenhuma das três partes de Ulisses. Na primeira parte, por exemplo, traduz Stalely por "Majestoso".

A tradução de Galindo tem ainda características próprias, uma delas diz respeito ao uso das vírgulas e do hífen. Joyce não gostava de vírgulas nem de hífens e os dispensava quando podia. O primeiro trecho, na tradução de Galindo, com apenas quatro vírgulas, o mesmo número utilizado por Joyce, parece mais joyceano do que as de seus antecessores, que utilizaram duas vírgulas a mais (parece pouco, mas talvez não seja). Esse cuidado com a pontuação foi uma preocupação de Galindo ao longo de sua tradução.

A tradução de Galindo conserva também a exuberância de palavras aglutinadas muito usadas por Joyce: "meiascoroas", "mãosleves", "caradecarne", "maisqueperfeita", "quintafeira", como se lê no primeiro capítulo de sua tradução de Ulysses.

Esses poucos exemplos demonstram o cuidado que Galindo teve em dialogar com o original, sem deixar escapar as referências mais diversas.

(Dirce Waltrick do Amarante)

\section{A língua portuguesa no tempo do embrião "i"}

Gostaria de falar rapidamente de duas traduções da obra máxima do século XX: Ulysses (1922), de James Joyce. Na verdade, para ser preciso, comentarei um trecho dessa obra volumosa, na tradução de Caetano Galindo, citando en passant as duas outras que temos no Brasil.

A tradução de Antônio Houaiss, lançada em meados do século passado, ainda tem meu apreço - eu a conheço bem, pois a li várias vezes. No entanto, hoje, depois de ler também a tradução de Caetano Galindo, posso declarar sem medo de errar que a tradução de Houaiss é uma tradução histórica, mas não a tradução que se deva ler hoje para fruir o romance de Joyce em nosso idioma, o português do Brasil. Parece-me que cada época possui a tradução que mais lhe convém, e, neste momento, a tradução que mais nos convém é a mais recente.

Mal conheço, porém, a tradução do mesmo romance de Joyce lançada tempos atrás pela professora Bernardina Pinheiro. Não consegui ler o seu texto porque, ao consultar o livro, busquei certas passagens que me são caras e não aprovei o que li.

Cito um caso, para mim decisivo. Numa passagem do romance de Joyce, atua o músico português Enrique Flor (cf. o episódio 12, "Cyclops"). Por várias razões, esse personagem é muito importante para mim. Meu último livro de poesia, Totens (Iluminuras, 2012), por exemplo, resgata a sua história e desenvolve bastante a biografia de Flor. Oriundo de um Portugal totalmente desmatado, Flor chega à Irlanda (país que perdera 99\% de sua mata nativa) e imediatamente põe em prática a música vegetal: ao tocar sua música mágica ou ecológica, folhas, galhos, flores 


\section{TELEMACHUS E A LÍNGUA EMBRIONÁRIA DE JOYCE}

começam a brotar por todo canto, inclusive, ou sobretudo, nos nomes e sobrenomes dos moradores de Dublin.

Para meu espanto, Pinheiro não traduz essa passagem, mas a deixa "em inglês", na sua versão de Ulysses. Houaiss se deu ao trabalho de recriar em português os nomes e sobrenomes ecológicos inventados por Joyce. O mesmo caminho foi seguido por Caetano Galindo. Flor continua, graças aos dois tradutores citados, a florescer em português, exceto na tradução de Pinheiro, o que lamento muito. Por esse motivo não tenho muito interesse em ler a tradução dela. Não me parece que essa tradução deva ser considerada, em suma, a tradução da nossa época.

Curiosamente, Enrique Flor quase desapareceu da tradução de Caetano Galindo. Teria sido a tragédia tradutória do ano, pelo menos para mim. O simpático tradutor revelou isso num evento em São Paulo, no Bloomsday de 2012, ao qual eu também compareci, com a minha mulher Dirce Waltrick do Amarante e alguns joycistas amigos. Então posso repetir aqui o que ele disse lá (somos grandes amigos), sem incorrer em indesculpável indiscrição. (Que o leitor me perdoe esse excesso de "in", tal aliteração canhestra não é nenhuma tentativa minha de ser joyciano ao falar de Joyce.)

Em poucas palavras, Galindo contou que, num dado momento, já no final da revisão de tradução, o músico português havia se transformado em músico húngaro. O tradutor tomou essa decisão para talvez recuperar o "estranhamento" que a menção a um músico português devia suscitar nos leitores irlandeses do século passado. Portugal estava tão distante do universo cultural da Irlanda quanto a Hungria do Brasil. Não discuto isso, mas a desaparição de Flor seria algo lamentável, já que Portugal, sem árvores, descobrira, no romance de Joyce, por intermédio da música vegetal, um inesperado renascer.

Num encontro na minha casa, em Florianópolis, o tradutor e poeta Paulo Henriques Britto contou-me que estava relendo a tradução do Galindo com o próprio. À minha menção ao nome de Flor, ele me revelou pela primeira vez que não havia mais Flor português no livro. Incrédulo, pedi ao Paulo Henriques que explicasse ao Galindo o meu desapontamento e o motivo dele. Mais tarde, troquei emails com o tradutor e repeti meus argumentos. Eis o final da história: o que era húngaro voltou a ser novamente português e a nova tradução do romance de Joyce se tornou merecedora, definitivamente, do título de melhor tradução da nossa época.

Lembro-me que Paulo Henriques comentou com admiração a tradução do episódio 14 do romance, conhecido como "Oxen of the Sun". No livro Ulysses Annotated, lemos o seguinte a respeito desse episódio: "Time: 10:00 P.M. Scene: the National Maternity Hospital, 20-31 Holles Street, Dublin. Organ: womb; Art: medicine; Color: White; Symbol: mothers; Techinque: embryonic development; [...]” (1988, p. 408).

O episódio é bastante complexo e não posso resumi-lo aqui nem levantar todas as suas implicações mitológicas, literárias, simbólicas, existenciais etc. Mas quero chamar a atenção para a técnica usada por Joyce, que remete à formação literária da língua. Caetano Galindo, com muita felicidade, traça, na sua tradução, a evolução da língua portuguesa. E, na história do nosso português, segundo Galindo, 


\section{Dirce Waltrick do Amarante \& SÉRgio Medeiros}

sobressai uma diminuta partícula, o “i”, que depois cresceu, evoluiu... Numa nota de rodapé, lemos no Ulysses Annotated: "In structure this episode is a series of imitations of prose styles presented in chronological sequence from Latin prose to fragments of modern slang" (1988, p. 408).

Eis o embrião “i”, ou o “i” embrionário, no texto do Ulysses brasileiro:

Daquela casa A. Horne é senhor. Setenta leitos ele i mantém por que as madres na sua hora delas i venham parir e dar à luz crias sãs como o anjo de Deus a Maria disse. Cuidosas cuidam i duas, seguem espertas. Seguiam espertas na ala irmãs brancas. Maladias pensavam dando gasalhado aos enfermos: em doze luas três vezes um cento. Ambas as duas excelentes guardiãs dos leitos eram, para Horne guardando a ala cuja dele era.

$[\ldots]$

$\mathrm{O}$ homem que à casa viera falou então à enfermeira e perguntou-a uma pergunta. Que desejava saber como calhasse estar a mulher que no leito de parto jazia i (2012, p.604-606).

O viandante Leopoldo também foi nessa manhã do dia 16 de junho ao castelo-maternidade, "por celebrar com os que i eram", o seu "filho" Estêvão estava incluído nesse rol.

(Sérgio Medeiros)

\section{Dirce Waltrick do Amarante} dwa@matrix.com.br

Profa. doutora, Universidade Federal de Santa Catarina

Sérgio Medeiros

panambi@matrix.com.br

Prof. doutor, Universidade Federal de Santa Catarina 